\title{
Loss of Cyp11c1 causes delayed spermatogenesis due to the absence of 11-ketotestosterone
}

\author{
Qiaoyuan Zheng1', Hesheng Xiao', Hongjuan Shi', Tingru Wang1', Lina Sun1', Wenjing Tao1, Thomas D Kocher², \\ Minghui Li' ${ }^{1}$ and Deshou Wang'
}

${ }^{1}$ Key Laboratory of Freshwater Fish Reproduction and Development (Ministry of Education), Key Laboratory of Aquatic Science of Chongqing, School of Life Sciences, Southwest University, Chongqing, China

2Department of Biology, University of Maryland, College Park, Maryland, USA

Correspondence should be addressed to M Li or D Wang: limh@163.com or wdeshou@swu.edu.cn

\begin{abstract}
The impacts of androgens and glucocorticoids on spermatogenesis have intrigued scientists for decades. 11 $\beta$-hydroxylase, encoded by cyp $11 c 1$, is the key enzyme involved in the synthesis of 11-ketotestosterone and cortisol, the major androgen and glucocorticoid in fish, respectively. In the present study, a Cyp11c1 antibody was produced. Western blot and immunohistochemistry showed that Cyp11c1 was predominantly expressed in the testicular Leydig cells and head kidney interrenal cells. A mutant line of cyp11c1 was established by CRISPR/Cas9. Homozygous mutation of cyp11c1 caused a sharp decrease of serum cortisol and 11-ketotestosterone, and a delay in spermatogenesis which could be rescued by exogenous 11-ketotestosterone or testosterone, but not cortisol treatment. Intriguingly, this spermatogenesis restored spontaneously, indicating compensatory effects of other androgenic steroids. In addition, loss of Cyp11c1 led to undersized testes with a smaller efferent duct and disordered spermatogenic cysts in adult males. However, a small amount of viable sperm was produced. Taken together, our results demonstrate that cyp11c1 is important for testicular development, especially for the initiation and proper progression of spermatogenesis. 11-ketotestosterone is the most efficient androgen in tilapia.
\end{abstract}
Key Words
- cyp11c1
- 11-ketotestosterone
- delayed spermatogenesis
- undersized testis
- less semen
- CRISPR/Cas9

\section{Introduction}

Spermatogenesis is a highly organized and coordinated process during which a small number of diploid spermatogonial stem cells, the founder cells of the germ line, develop through mitosis, meiosis and differentiation into the haploid spermatozoa (Schulz et al. 2010, Chocu et al. 2012, Nishimura \& L'Hernault 2017). Androgens are among the main hormones involved in spermatogenesis and male sexual development in vertebrates (Schulz \& Miura 2002, Walker 2010, Smith \& Walker 2014). The biological functions of androgens are primarily mediated by the androgen receptor (AR), a ligand-induced nuclear receptor, through binding to androgen response elements (AREs) in the regulatory regions of target genes (Bennett et al. 2010, O'Hara \& Smith 2015).

Androgens are synthesized from cholesterol by steroid synthases in a complex pathway that is largely conserved among vertebrates (Miller 1988). Despite the conservation in steroid synthesis, preferences for androgen use were found in vertebrates. In mammals, testosterone is thought to be the predominant androgen in testis 
(Smith \& Walker 2014). Testosterone alone could maintain spermatogenesis in vitro (Cunningham \& Huckins 1979). Disruption of testosterone production by hypophysectomy, Leydig cell ablation, luteinizing hormone receptor mutation or cyp17a1 deletion blocked spermatogenesis in mice and rats (Russell \& Clermont 1977, Bartlett et al. 1986, Zhang et al. 2001, Liu et al. 2005). In fish, 11-ketotestosterone (11-KT) is generally considered to be a more effective androgen, notwithstanding the high levels of serum testosterone (Nakamura \& Nagahama 1989, Borg 1994). The role 11-KT in fish spermatogenesis became clear for the first time in 1991, using an organ culture system in vitro (Miura et al. 1991), and then repeatedly confirmed in different species (Kobayashi et al. 1991, Cavaco et al. 1998, Amer et al. 2001). 11ß-Hydroxylase, encoded by cyp11c1, is the key enzyme involved in 11-KT synthesis. Elevated expression of 11ß-hydroxylase results in high levels of 11-KT during the crucial period of spermatogenesis (Kusakabe et al. 2002, Rajakumar \& Senthilkumaran 2015). Although the androgenic potency of 11-KT has been determined in various species (Kobayashi et al. 1991, Miura et al. 1991, Cavaco et al. 1998, Amer et al. 2001, de Waal et al. 2008, Bain et al. 2015), the precise role of $11-\mathrm{KT}$ in spermatogenesis remains to be elucidated by a genetic approach.

Cortisol, another steroid synthesized by 11ß-hydroxylase, has been regarded as the main glucocorticoid in teleost fish, linking external environmental stimuli with internal physiological responses during sexual development (Mommsen et al. 1999, Todd et al. 2016). Although several hypotheses exist, studies on the exact ways in which cortisol may act as a mediator in the masculinization process are still limited (Consten et al. 2002, Hayashi et al. 2010, Fernandino et al. 2012). It is worth mentioning that cortisol was demonstrated to promote spermatogenesis by inducing spermatogonial proliferation through the synthesis of 11-KT in Japanese eel testis explants (Ozaki et al. 2006). This still needs to be verified in vivo.

Nile tilapia (Oreochromis niloticus) is farmed worldwide. It has an XX/XY sex-determination system. The availability of genetic unisexual fish (Sun et al. 2014), 14-day spawning cycle, together with high-quality genome sequences (Conte et al. 2017) and well-established reverse genetics approaches (Li et al. 2014), make tilapia an ideal model to investigate the role of steroids in spermatogenesis. In our previous study we cloned cyp11c1 and analyzed its expression in Nile tilapia (Zhang et al. 2010). To further decipher the role of 11-KT and cortisol in spermatogenesis, we used CRISPR/Cas9 to generate a line mutant for cyp11c1 and conducted a comprehensive assessment of cyp11c1 mutant males, including gonadal phenotypes, serum hormone levels, sperm quality and fecundity. Our research provides a better understanding of the role of 11-KT and cortisol in fish spermatogenesis.

\section{Materials and methods}

\section{Animals}

Nile tilapia (Oreochromis niloticus) were kept in aerated recirculating freshwater tanks at $26^{\circ} \mathrm{C}$ under a natural photoperiod. All XX progenies were obtained by crossing $\mathrm{XX}$ pseudomales (producing sperm after hormonal sex reversal) with $\mathrm{XX}$ females. All XY progenies were obtained by crossing YY supermales with XX females. Animal experiments were conducted in accordance with the regulations of the Guide for Care and Use of Laboratory Animals and were approved by the Committee of Laboratory Animal Experimentation at Southwest University.

\section{Production and characterization of Cyp11c1 polyclonal antibody}

The recombinant construct of cyp11c1 was prepared by cloning cyp11c1 coding sequence into the EcoRI and Sal I restriction site of the pCold I prokaryotic expression vector with His-tag at the N-terminus. This recombinant plasmid was then transformed into Escherichia coli, followed by IPTG induction ( $1 \mathrm{mmol} / \mathrm{L})$. The His-Cyp11c1 recombinant protein $(25-30 \mu \mathrm{g})$, purified with a Ni-NTA super flow cartridge (Qiagen), was subsequently used as antigen to immunize rabbits three times at 15-day intervals. Ten days after the last immunization, rabbit blood was collected, and Cyp11c1specific antibody was purified by affinity chromatography on Sepharose 4B Fast Flow resin (Sigma) with a stock concentration of $2 \mathrm{mg} / \mathrm{mL}$. The antibody specificity was subsequently evaluated by Western blot at a dilution of 1:500. The negative control (NC) was incubated with preadsorbed antisera with purified Cyp11c1 protein. Primers used in this experiment are listed in Supplementary Table 1 (see section on supplementary materials given at the end of this article).

\section{Cellular localization of Cyp11c1}

Immunohistochemistry (IHC) was performed to determine cellular localization as described previously 
(Zhang et al. 2010). After anesthesia (250 mg/L, MS-222, Sigma), testes from 5, 30, 90 and 180 dah (days after hatching) fish and head kidneys from 1, 30, 90 and 180 dah fish were collected and fixed immediately in Bouin's fixative solution for $24 \mathrm{~h}$ at room temperature. Samples were then dehydrated and embedded in paraffin. Tissue blocks were serially sectioned at $5 \mu \mathrm{m}$. Antibody against Cyp11c1 was diluted at 1:500 for use.

\section{Disruption of cyp11c1 by CRISPR/Cas9}

The sequence of cyp11c1 (ENSONIG00000006462) was obtained from Ensembl (http://www.ensembl.org/ index.html). The target site in the coding region of the first exon of cyp11c1 was selected with an online software package (http://zifit.partners.org/ZiFiT/), and the gRNA (guide RNA) and cas9 mRNA were synthesized as previously reported (Li et al. 2014). Embryos at the one-cell stage were microinjected with gRNA and Cas9 mRNA with a final concentration of $250 \mathrm{ng} / \mu \mathrm{L}$ and $500 \mathrm{ng} / \mu \mathrm{L}$, respectively. F0 mutants were screened by $\mathrm{MluCI}$ restriction enzyme digestion and Sanger sequencing. F1 progeny were produced by crossing F0 chimeric XY males with WT XX females. Siblings carrying a $7 \mathrm{bp}$ deletion at the same locus were intercrossed to produce F2 progeny. PAGE was used to identify mutants in the F2 generation. The genetic sex of each fish was identified by sex-linked marker as described previously (Sun et al. 2014). Primers used for screening are listed in Supplementary Table 1.

\section{qPCR}

Pituitaries and testes were collected from cyp11c1 ${ }^{+/+}$and cyp11c1-/- fish at 360 dah ( $n=4 /$ genotype). RNA was isolated for each replicate using RNAiso Plus (Takara). 500 ng RNA was used for cDNA synthesis with PrimeScript RT Master Mix Perfect Real Time Kit (Takara). Gene expression was analyzed by qPCR (quantitative real-time PCR) using ABI7500 Detection system. All experiments were performed according to the manufacturer's instructions. Gene expression was normalized to gapdh using the $2^{-\Delta \Delta \mathrm{Ct}}$ method (Livak \& Schmittgen 2000). Primers used for quantitation are listed in Supplementary Table 1.

\section{Western blot}

Total protein, extracted from various tissues of adult WT fish and gonads of $c y p 11 c 1^{+/+}$and $c y p 11 c 1^{-/-} \mathrm{XY}$ fish at 180 dah, was diluted to a final concentration of $20 \mathrm{mg} / \mathrm{mL}$.
A Western blot (WB) was performed as described previously (Li et al. 2012) using anti-Cyp11c1 antibody diluted 1:500. The abundance of $\alpha$-tubulin was examined as a loading control using rabbit anti- $\alpha$-tubulin with a dilution ratio 1:1000 (Abcam, AB2619646). Horseradish peroxidaseconjugated goat anti-rabbit antibody (Beyotime, Shanghai, China, A0208) was diluted 1:1000 as secondary antibody. Signal was detected with Western Bright ECL Kit (Advansta, CA, USA, lot 19011532) and visualized on a Fusion FX7 (Vilber Lourmat, East Sussex, France).

\section{Histological analysis}

The gonadosomatic index (GSI) of cyp11c1 $1^{+/+}$and cyp11c1-/- fish at 360 dah was calculated as (gonad weight/ body weight $\times 100 \% \quad(n=4 /$ genotype $)$. Testes processed for histology were embedded in paraffin after fixation in Bouin's solution (24 h, RT). Embedded samples were then cut serially into slices of $5 \mu \mathrm{m}$ for hematoxylin and eosin (H\&E) staining and immunohistochemistry as described previously (Zhang et al. 2010). The anti-PH3 (Phospho S10 of histone H3, Abcam, ab80612) and anti-Cyp17a2 ( $2 \mathrm{mg} / \mathrm{mL}$ ) polyclonal antibody were used to assess the impacts of cyp11c1 mutation on cell proliferation and steroidogenic properties, respectively, with a 1:1000 dilution. All sections were imaged using an Olympus BX51 optical microscope (Olympus). The relative areas of efferent ducts and Leydig cells (Cyp17a2-positive) in testes from fish at 360 dah were calculated by Image J Pro 1.51 (mid-section, $n=4 /$ genotype).

\section{Semen analysis and fecundity evaluation}

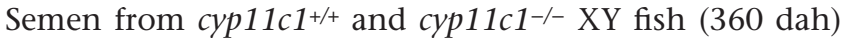
was evaluated comprehensively ( $n=5 /$ genotype). Sperm morphology and motility, including VSL (straight line velocity), VCL (curvilinear velocity) and BCF (beat cross frequency), were assessed using the Sperm Quality Analyzer (Zoneking Software, Beijing, China). Sperm motility was finally graded as A (rapid motion forward), B (slow motion forward), C (no forward motion) or D (hyperslow or motionless). To further check the spermfertilizing ability of $c y p 11 c 1^{-1-} \mathrm{XY}$ fish, an excess of semen from $c y p 11 c 1^{+/+}$and $c y p 11 c 1^{-/-} \mathrm{XY}$ fish was used to inseminate eggs from WT XX fish.

\section{Rescue experiments}

After randomized grouping, the cyp11c1-/- XY fish were fed with a diet sprayed with 95\% ethanol containing 
11-KT, testosterone, cortisol at a $200 \mu \mathrm{g} / \mathrm{g}$ dosage respectively or $95 \%$ ethanol only (ctrl). Treatment were administrated from 30 to 75 dah, fish were then supplied with a normal diet until sampling at 90 dah. Thereafter, treatment was evaluated by $\mathrm{H} \& \mathrm{E}$ staining. All images were captured by Olympus BX51 optical microscope (Olympus). Spermatogenic cells including spermatogonia, spermatocytes, and spermatids from the median cross section of the testes were further quantified manually ( $n=5$ /administration), primarily based on cell size, nuclear characteristics (degree of chromosome condensation) and location in testis.

\section{EIA measurement of serum 11-KT, testosterone, cortisol and DHT level}

After anesthesia, blood was collected from the caudal vein of $c y p 11 c 1^{+/+}, c y p 11 c 1^{+/-}$and $c y p 11 c 1^{-/-} \mathrm{XY}$ fish at 90 and 180 dah. After overnight storage at $4^{\circ} \mathrm{C}$, more than $100 \mu \mathrm{L}$ of serum was collected by centrifugation (2656 $\mathrm{g}, 10 \mathrm{~min}, 4^{\circ} \mathrm{C}$ ) and stored at $-80^{\circ} \mathrm{C}$ until use. Serum 11-KT, testosterone, cortisol (Cayman) and $5 \alpha$-dihydrotestosterone (DHT, Spbio, Wuhan, China) were analyzed using Enzyme Immunoassay (EIA) Kit according to the manufacturer's instructions. The sensitivity of the kit for 11-KT, testosterone, cortisol and DHT is 1.3, 6.0, 35.0 and $14.7 \mathrm{pg} / \mathrm{mL}$, respectively. $50 \mu \mathrm{l}$ diluted serum (based on the assay sensitivity of each kit) was used for each well. All samples (serum from single fish as one sample, $n=6 /$ genotype) were run in triplicate on one 96-well plate for measurement of each steroid in one assay to ensure the comparability. The intra-assay coefficients of EIA are listed in Supplementary Table 2.

\section{Statistical analysis}

Values are presented as mean \pm s.D. A two-tailed independent Student's t-test was used to determine the differences between two groups. One-way ANOVA, followed by Tukey multiple comparison, was chosen for tests involving more than two groups. The relative frequency of sperm grades between the mutant and wild type fish was compared by chi-squared test. All analyses were performed using SPSS 22.0 (IBM). Thresholds corresponding to $P<0.05$ were used to identify statistically significant differences.

\section{Results}

\section{Antibody verification and Cyp11c1 expression in developing gonad and head kidney}

Unpurified and purified recombinant Cyp11c1, as well as total proteins extracted from 180 dah ovaries and testes, were analyzed by SDS-PAGE with Coomassie blue staining (Fig. 1A). The specificity of the anti-Cyp11c1 polyclonal antibody was confirmed by Western blot. Specific bands,

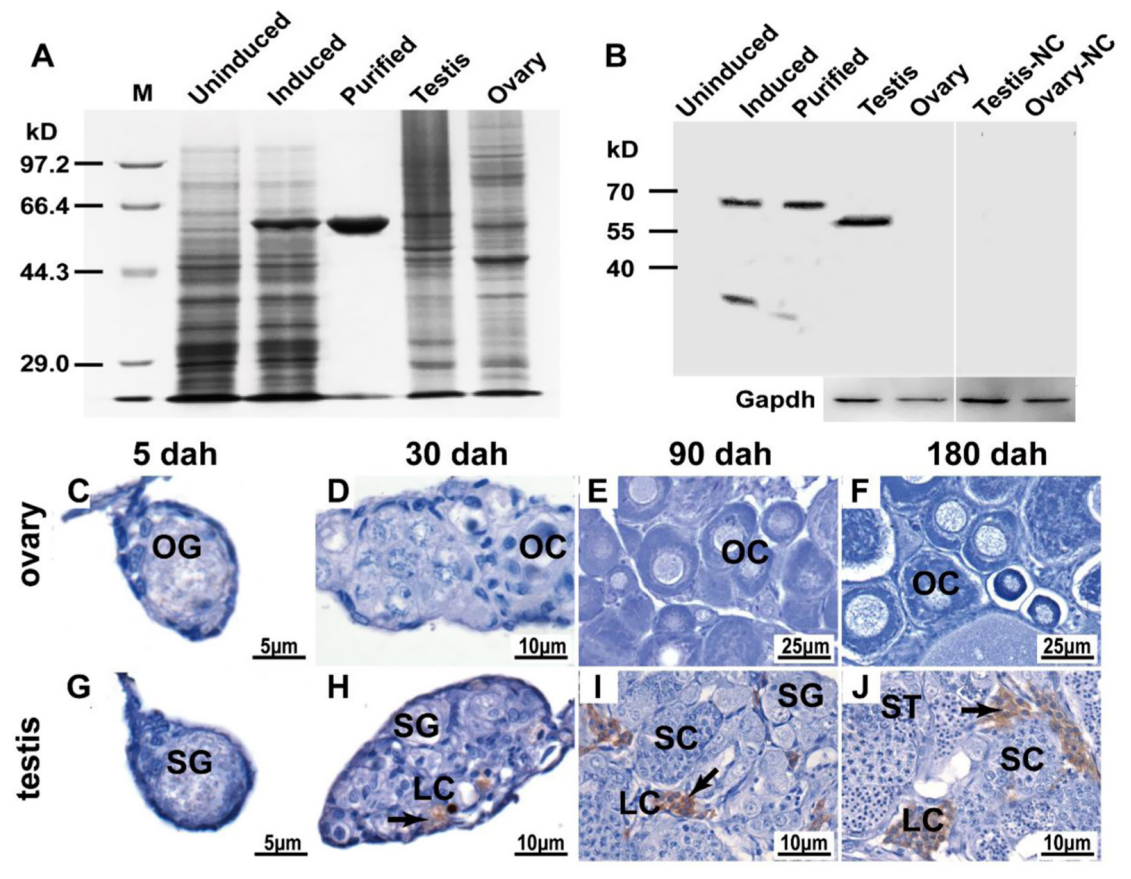

\section{Figure 1}

Cyp11c1 was specifically expressed in testicular Leydig cells. (A) SDS-PAGE and Coomassie blue staining of proteins from uninduced, IPTGinduced His-Cyp11c1-pCold I positive E. coli, together with purified His-Cyp11c1 protein and proteins from Nile tilapia testes and ovaries. (B) Specificity verification of anti-Cyp11c1 polyclonal antibody by Western blot. NC, negative control to show the staining in the ovaries and testes was diminished by addition of competing purified Cyp11c1 antigen. (C, D, E, f, G, H, I and J) Cellular localization of Cyp11c1 in testes and ovaries at 5, 30, 90 and 180 dah. Arrows, Cyp11c1-positive cells; OG, Oogonia; OC, Oocytes; SG, Spermatogonia; SC, Spermatocytes; ST, Spermatids; LC, Leydig cells; dah, days after hatching. 
corresponding to the calculated molecular weight of the tilapia Cyp11c1 with N-terminal His-tag (63.36 kD) and the native protein $(60.12 \mathrm{kD})$ were recognized (Fig. 1B). By Western blot, Cyp11c1 was found to be expressed in testis and head kidney, but not in ovary, brain, gill, heart, liver, gut or skeletal muscle (Supplementary Fig. 1). By IHC, Cyp11c1 was predominantly expressed in the testicular Leydig cells at 30, 90, 180 dah (Fig. 1H, I and J) and head kidney interrenal cells at 1, 30, 90, 180 dah (Supplementary Fig. 1). No specific immunostaining was observed in testes at 5 dah or in ovaries at any developmental stage (Fig. 1C, D, E, F and G).

\section{Establishment of cyp11c1 mutant line by CRISPR/Cas9}

To investigate the exact role of 11-KT in spermatogenesis, we generated a cyp11c1-knockout model in tilapia by CRISPR/Cas9 (Fig. 2A). The target site with a MluCI restriction site (marked red) is located in the first exon of cyp11c1. The mutation rate in pooled embryos was approximately $71 \%$. Mutation was further confirmed by Sanger sequencing (Fig. 2B). F1 siblings, obtained by crossing mosaic FO XY fish with wild type XX, with a 7 bp deletion in the coding region of the first exon, were intercrossed to produce F2 progeny (Fig. 2C). Homozygous F2 were successfully identified by PAGE (Fig. 2D). Further analysis of this mutation revealed a truncated protein due to the premature termination of cyp11c1 translation (Fig. 2E). The ablation of Cyp11c1 was further validated by Western blot (Fig. 2F) and immunohistochemistry (Fig. 2G). Cyp11c1 protein was undetectable in testis.

\section{Mutation of cyp11c1 resulted in delayed spermatogenesis}

Anti-PH3 polyclonal antibody was used to evaluate cell proliferation capacity in testes. Aberrant spermatogenesis, with only spermatogonia accompanied by decreased proliferation, was observed in $c y p 11 c 1^{-/-}$testes at 90 dah (Fig. 3A and C). Strangely, this defect did not continue. Spermatogenesis was restored at $180 \mathrm{dah}$, as indicated by the existence of all stages of spermatogenic cells and normal proliferation (Fig. 3F and H). Given the critical role of Cyp11c1 in fish cortisol and 11-KT synthesis, serum cortisol and 11-KT level of $c y p 11 c 1^{+/+}$and $c y p 11 c 1^{-/-}$male were determined by EIA. A sharp decrease of cortisol and 11-KT were detected in $c y p 11 c 1^{-1-}$ male both at 90 and 180 dah (Fig. 3D, I, K and N), indicating a possible role of these two hormones in the initiation of fish spermatogenesis. To investigate the possible mechanisms for the restoration of spermatogenesis, serum levels of two other potent androgenic hormones, testosterone and its' $5 \alpha$-reduced derivative, DHT, were analyzed. A highly accumulated serum testosterone was detected in $c y p 11 c 1^{-/-}$males both at 90 and 180 dah (Fig. 3E and J), while elevated DHT level was found only at $180 \mathrm{dah}$ (Fig. 3L and O). It is noteworthy that the elevation of DHT might not be caused by the upregulation of the DHT synthase gene, srd5a1, but rather by accumulation of testosterone (Fig. 3M and P). Slightly delayed spermatogenesis was detected in $c y p 11 c 1^{+/-}$males (Fig. 3B and G), which was consistent with the decreased serum 11-KT and accumulated testosterone in both 90 dah and 180 dah male heterozygotes (Fig. 3D, E, I and J), indicating a dose-dependent action of cyp11c1 in fish spermatogenesis. Overall, loss cyp11c1 resulted in
A

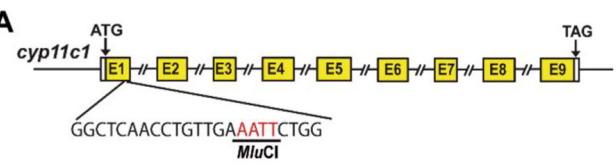

C

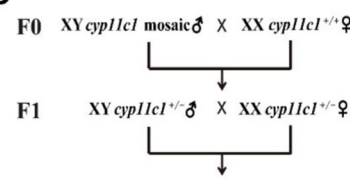

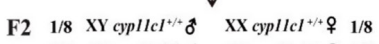

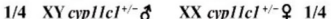

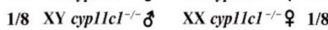

F

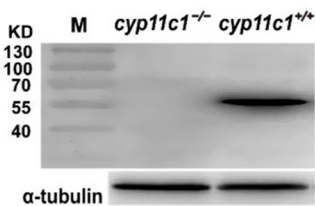

D

$$
\text { D }
$$
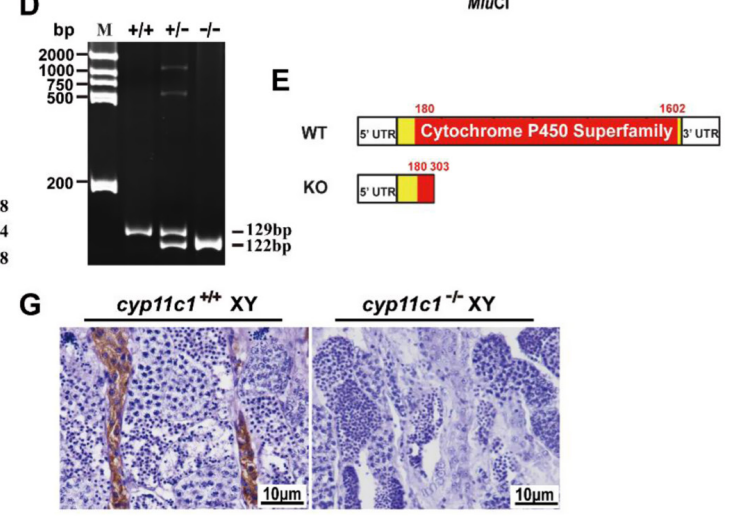

E

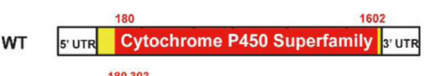

ко

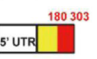

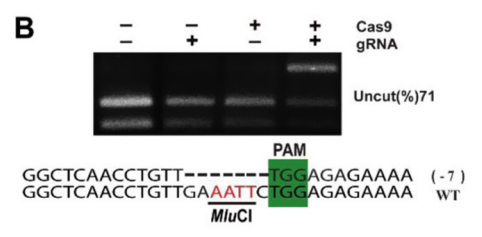

(c) 2020 Society for Endocrinology Published by Bioscientifica Ltd. Printed in Great Britain
Figure 2

Establishment of cyp11c1 mutant line by CRISPR/ Cas9. (A) Target site in cyp11c1. A target site with a $\mathrm{MluCl}$ restriction enzyme site (marked red) was identified in the first exon of cyp11c1. (B) Mutation detection by restriction enzyme digestion and Sanger sequencing. Deletions are marked with black dashes, PAM is highlighted in green. Red letters indicate the restriction site of $\mathrm{MluCl}$. (C) Generation of the F2 progeny. F1 siblings with a 7 bp deletion in the coding region of the first exon were intercrossed for F2 progeny. (D) Mutation identification by PAGE. Wild type, heterozygotes and homozygotes were indicated by ' $+/{ }^{\prime}{ }^{\prime},{ }^{\prime}+/{ }^{\prime}$ and '- $/$ ', respectively. (E) Cyp11c1 protein sequence prediction. 'WT' and 'KO' represent wild type and knockout, respectively. ( $F$ and $G$ ) Validation of cyp11c1 knockout at 180 dah by Western blot and immunohistochemistry. The positive signal corresponds to brownish color. 


\begin{tabular}{l|l|l|r|r|}
$\begin{array}{l}\text { Journal of } \\
\text { Endocrinology }\end{array}$ & Q Zheng et al. & $\begin{array}{l}\text { Role of cyp11c1 in } \\
\text { spermatogenesis in tilapia }\end{array}$ & $\mathbf{2 4 4 : 3}$ & $\mathbf{4 9 2}$ \\
\hline
\end{tabular}
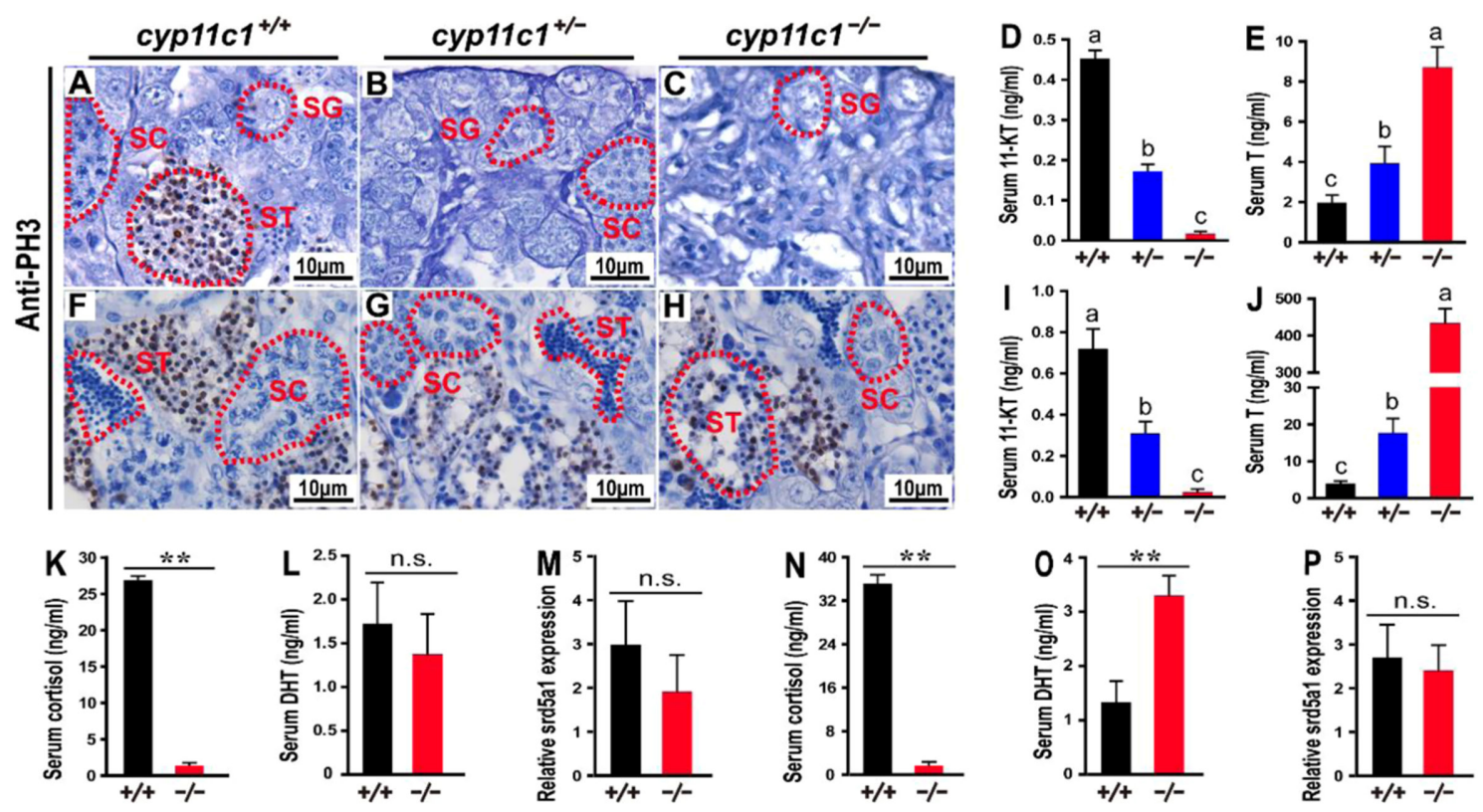

Figure 3

Mutation of cyp11c1 resulted in delayed spermatogenesis. (A, B and C) PH3 staining of cyp11c1+/+ (A), cyp11c1+/- (B) and cyp11c1-/- (C) testis at 90 dah. (D and E) EIA measurement of serum 11-KT (D) and testosterone (T) (E) level of cyp11c1+/+, cyp11c1 ${ }^{+/-}$and cyp11c1-/- male fish at 90 dah. (F, G and H) PH3 staining of $c y p 11 c 1^{+/+}(\mathrm{F})$, cyp11c1+/- $(\mathrm{G})$ and cyp11c1-/- $(\mathrm{H})$ testis at 180 dah. (I and J) ElA measurement of serum 11-KT (I) and testosterone (T) $\mathrm{J}$ ) level of

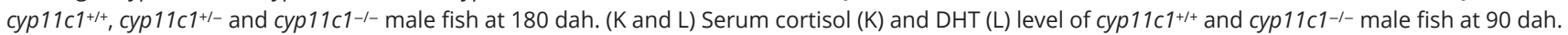
(M) Relative srd5a1 mRNA expression of cyp11c1+/+ and cyp11c1-/- male fish by qPCR at 90 dah. (N and O) Serum cortisol (N) and DHT (O) level of

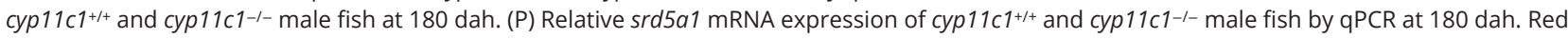
dotted lines outline spermatogonia (SG), spermatocytes (SC), spermatids (ST). The PH3 positive signal corresponds to brownish color. Values are

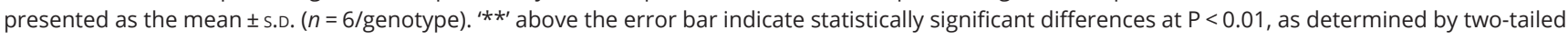
independent Student's $t$-test. Significant differences of serum 11-KT and testosterone level between cyp 11c1 ${ }^{+/+}, c y p 11 \mathrm{c} 1^{+/-}$and cyp $11 \mathrm{c} 1^{-/-}$group are indicated by different letters, as determined by one-way ANOVA followed by Tukey test for multiple comparisons $(P<0.05)$.

a delayed spermatogenesis, which might be caused by the deficiency of cortisol or 11-KT. The increased serum testosterone, thereafter, is likely a major contributor toward the restoration of spermatogenesis.

\section{Delayed spermatogenesis could be rescued by exogenous 11-KT and testosterone, but not cortisol}

To determine the major cause of delayed spermatogenesis at 90 dah, we analyzed $c y p 11 c 1^{-/-}$males after administration of 11-KT and cortisol. We also compared the androgenic potency of testosterone with 11-KT in the initiation of spermatogenesis. Normal spermatogenesis with various stages of spermatogenic cells was observed in the testes after 11-KT and testosterone treatment (Fig. 4B, C, B' and $\mathrm{C}^{\prime}$ ), while spermatogenesis in the testes treated with cortisol was still aberrant (Fig. 4D and $\mathrm{D}^{\prime}$ ). To quantify these effects, we calculated cell numbers and relative proportions of spermatogenic cell types (Fig. 4E and F). Consistently, the testes with 11-KT and testosterone administration showed a relatively normal cell proportion (Fig. 4F). In addition, 11-KT displayed a higher androgenic potency than testosterone, as reflected by a lower percentage of spermatogonia and spermatocytes, and higher percentage of spermatids (Fig. 4F). Collectively, these findings suggested that the aberrant spermatogenesis in $c y p 11 c 1^{-/-}$ at 90 dah was mainly caused by the deficiency of $11-\mathrm{KT}$, and not cortisol. 11-KT has a higher androgenic potency than testosterone.

\section{Cyp11c1 ablation led to undersized testes and lower spermatogenic efficiency}

The restored spermatogenesis of $c y p 11 c 1^{-/-}$fish raised the question whether fish can develop a completely normal testis in the absence of 11-KT. We therefore analyzed testicular size, structure, spermatogenic efficiency and steroidogenic potency of cyp11c1-/- fish at 360 dah. Despite the restored spermatogenesis, undersized testes with a relatively smaller efferent duct and disordered spermatogenic cysts were observed in cyp11c1-l- fish (Fig. $5 \mathrm{~A}, \mathrm{~B}, \mathrm{~A}^{\prime}, \mathrm{B}^{\prime}$ and $\left.\mathrm{E}, \mathrm{F}\right)$. In addition, $c y p 11 c 1^{-/-}$fish showed a lower spermatogenic efficiency as indicated by the reduced semen volume (Fig. 5G). Besides, $c y p 11 c 1^{-/-}$fish 


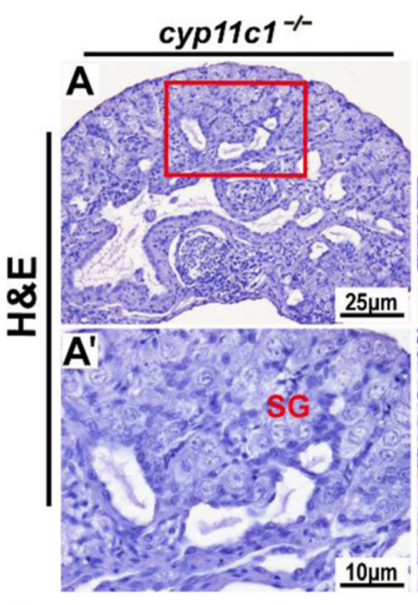

cyp11c1 $1^{-1}+11-\mathrm{KT}$

$\mathbf{E}$

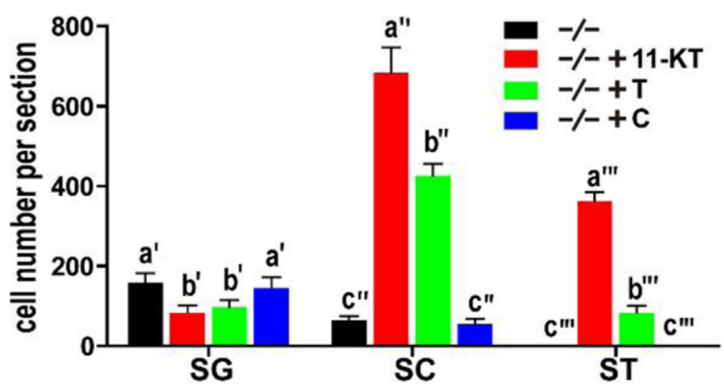

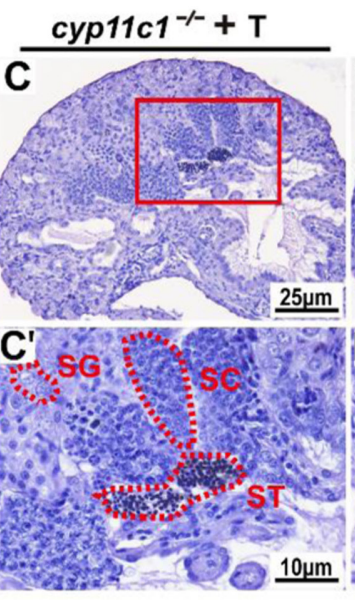

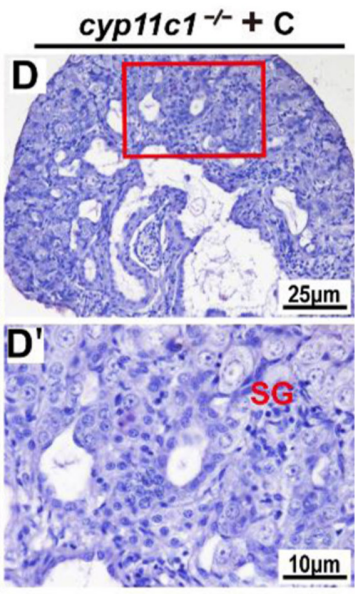

$\mathbf{F}$

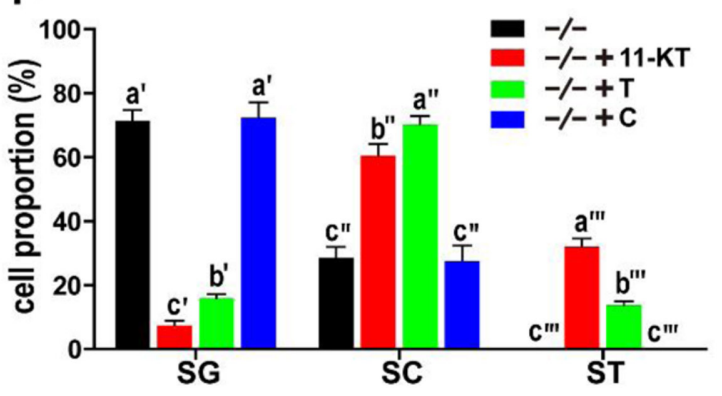

\section{Figure 4}

Delayed spermatogenesis in cyp11c1-/- fish can be rescued by exogenous 11-KT and testosterone treatment. (A, B, C, D, A', B', C' and D') H\&E staining of testes from fish at 90 dah after different treatment. Red dotted lines outline spermatogonia (SG), spermatocytes (SC), spermatids (ST). (E and F) Absolute cell number (E) and relative proportion (F) of spermatogenic cells from testes with different treatment. 11 KT, 11-ketotestosterone; T, testosterone; $C$, cortisol. Values are presented as the mean \pm S.D. ( $n=5$ /treatment). Significant differences of SG, SC and ST between different treatment are indicated by

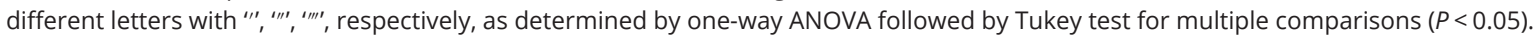

displayed a relatively reduced Leydig cell area, implying an impaired steroidogenic capacity (Fig. 5C, D, C', D' and H). These results demonstrated an abnormal morphology and compromised physiological function of cyp11c1-/- testes. These defects were not detected in adult cyp11c1+/- males (Supplementary Fig. 2). Considering the important role of gonadotropins in regulating steroidogenesis and testicular development, we further quantified the expression of $f s h b, l h b$ and their receptors, fshr, $l h r$ by qPCR. To our surprise, the mRNA levels of these genes were upregulated in $c y p 11 c 1^{-1-}$ fish (Fig. 5I).

\section{Effects of cyp11c1 mutation on sperm quality}

To get a more comprehensive assessment of the reproductive repertoire of $c y p 11 c 1^{-/-}$males, semen from cyp11c1+/+ and cyp11c1-/- fish was analyzed. Despite the reduced semen volume, cyp11c1-/- fish showed normal sperm morphology and motility as indicated by the similar trajectory and sperm BCF, VSL, VCL (Fig. 6A, B, C,
D, E and F). To better evaluate sperm motility, the sperm of $c y p 11 c 1^{+/+}$and $c y p 11 c 1^{-/-}$fish with different motility was further graded with A (rapid motion forward), B (slow motion forward), C (no forward motion) and D (hyperslow or motionless). No significant differences were found in the frequency of this four sperm grades between cyp11c1 $1^{+/+}$and cyp11c1-/- XY fish (Fig. 6G). These results revealed a normal sperm motility in cyp11c1-/- XY fish. We further analyzed the fertilization ability of sperm. No significant differences were found between sperm from cyp11c1+/+ and cyp11c1-/- fish (Fig. 6H). In conclusion, fish without 11-KT can produce a small amount of sperm with normal motility and fertilization ability.

\section{Discussion}

The impact of androgens and glucocorticoids on spermatogenesis has intrigued scientists for decades. cyp11c1 is the key enzyme gene involved in the 


\begin{tabular}{l|l|l|l|l|}
$\begin{array}{l}\text { Journal of } \\
\text { Endocrinology }\end{array}$ & Q Zheng et al. & $\begin{array}{l}\text { Role of cyp11c1 in } \\
\text { spermatogenesis in tilapia }\end{array}$ & $\mathbf{2 4 4 : 3}$ & $\mathbf{4 9 4}$ \\
\hline
\end{tabular}

H\&E

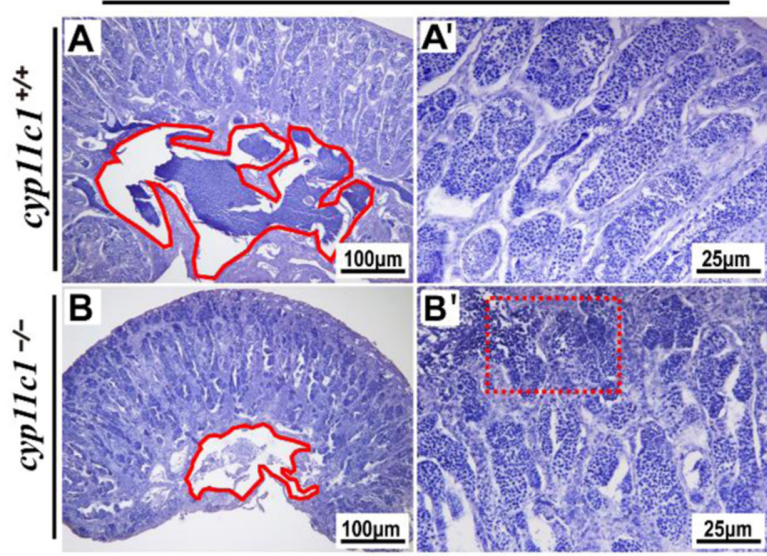

Anti-Cyp17a2

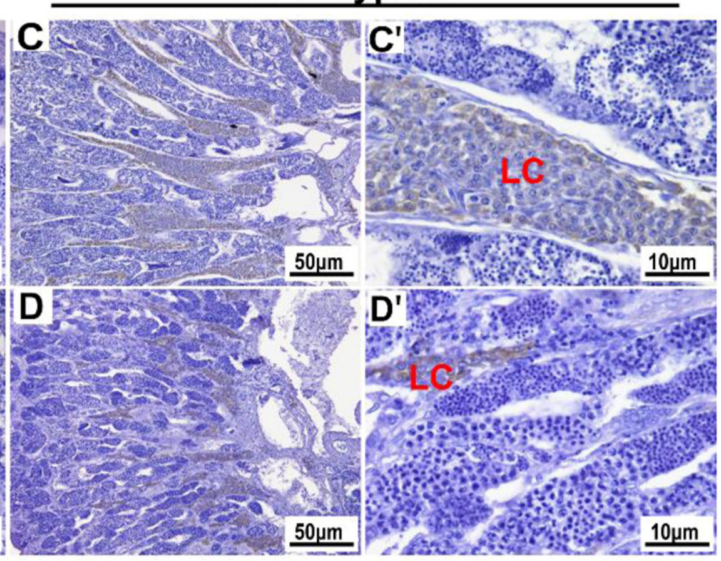

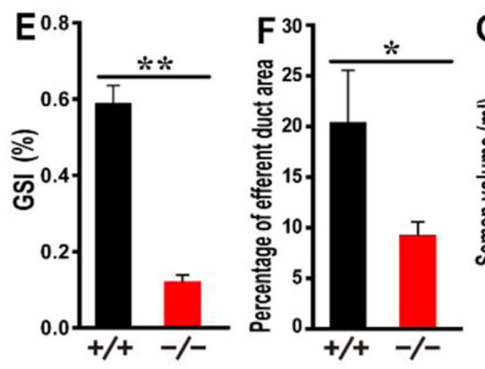
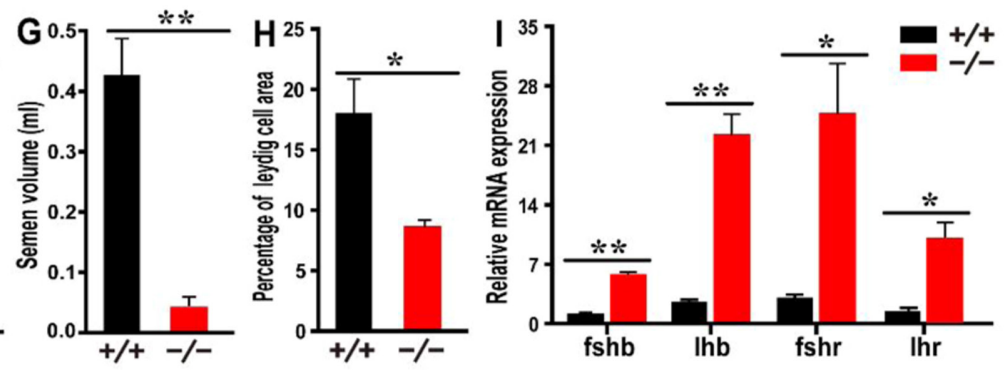

\section{Figure 5}

Mutation of cyp11c1 resulted in disordered spermatogenic cysts and less semen. (A, B, $A^{\prime}$ and $\left.B^{\prime}\right)$ H\&E staining of cyp11c1 $1 /++$ and cyp11c1-/- testis from fish at 360 dah. Red solid line outlines the efferent duct. Red dotted line highlights disordered spermatogenic cysts. (C, D, $C^{\prime}$ and $\left.D^{\prime}\right)$ Immunohistochemistry for the Leydig cell marker Cyp17a2 in cyp11c1+/+and cyp11c1-/- testis from fish at 360 dah. (E) GSI of cyp11c1+/+ and cyp11c1-/- male fish at 360 dah. (F) Percentage of efferent duct area per section at 360 dah. (G) Semen volume of $c y p 11 c^{1+/+}$ and cyp $11 c 1^{-/-}$fish. (H) Percentage of Leydig cell area per section. I) Relative mRNA expression of $f s h b, I h b, f s h r, I h r$ in $c y p 11 c 1^{+/+}$and cyp11c1-/- male at 360 dah. LC, Leydig cells. The positive signal corresponds to the brownish color. Values were presented as the mean \pm S.D. $(n=4$ /genotype). ' $*$ ' and ' $* *$ ' above the error bar indicate statistically significant differences at $P<0.05$ and $P<0.01$, respectively, by two-tailed Student's $t$-test.

synthesis of 11-KT and cortisol, the major androgen and glucocorticoid in fish, respectively. In the present study, Cyp11c1 was found to be predominantly expressed in the testicular Leydig cells and head kidney interrenal cells using specific antibodies. Through mutation of cyp11c1 and a rescue experiment, we demonstrated that cyp11c1 is important for the testicular development, especially for the initiation and proper proceeding of spermatogenesis.
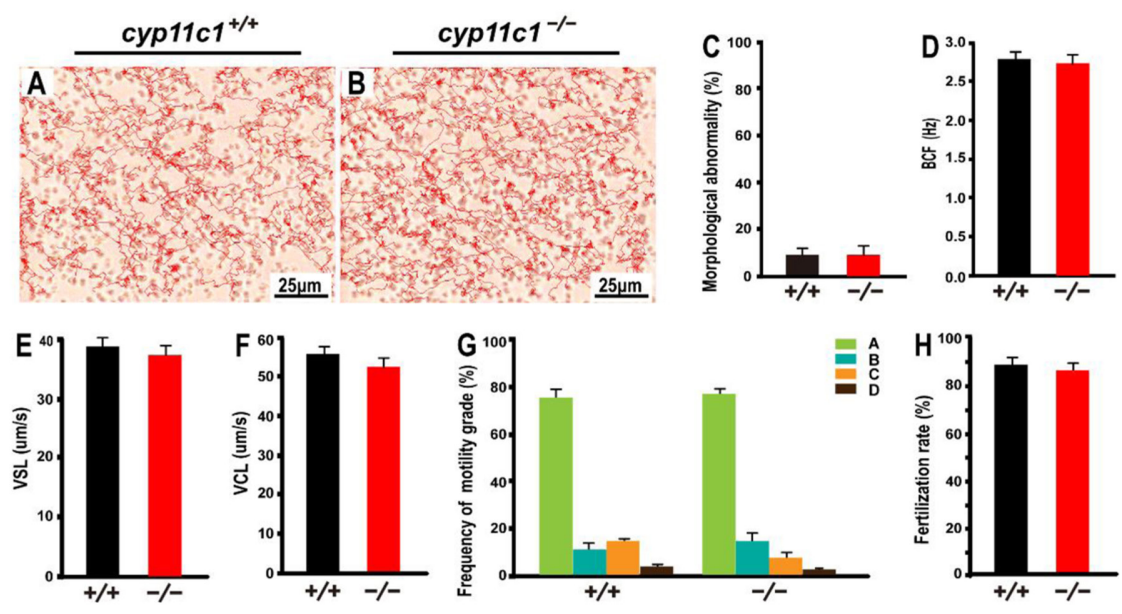

https://joe.bioscientifica.com https://doi.org/10.1530/JOE-19-0438
(C) 2020 Society for Endocrinology Published by Bioscientifica Ltd.
Printed in Great Britain

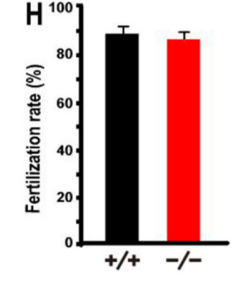

\section{Figure 6}

cyp11c1 mutation had no effect on sperm quality. (A and B) Sperm dynamic trajectory curve of cyp11c1+/+ and cyp11c1-l- fish (red line). (C, D, E and F) Evaluation of sperm morphology (C), BCF (D), VSL (E) and VCL (F). (G) Frequency of sperm motility grade. $(\mathrm{H})$ Fertilization ability assessment of cyp11 $11^{+/+}$and cyp11c1-/- sperm. BCF, beat cross frequency; VSL, straight line velocity; VCL, curvilinear velocity. Sperm motility grade $A$, rapid motion forward; B, slow motion forward; C, no forward motion; D, hyperslow or motionless. Values are presented as the mean \pm S.D. $(n=5 /$ genotype). Differences between two groups were determined by two-tailed independent Student's $t$-test. The relative frequency of four sperm grades was estimated by Chi-squared test. No significant differences were observed between the cyp $11 \mathrm{c1}^{+/+}$and cyp11c1-/- fish. 


\section{Cyp11c1 is expressed in Leydig cells and inter-renal cells in Nile tilapia}

Sexually dimorphic expression of cyp11c1 has been reported in a number of species (Jiang et al. 1996, Liu et al. 2000, 2009, Socorro et al. 2007). By in situ hybridization, cyp11c1 was shown to be expressed in the testicular Leydig cells in rainbow trout and zebrafish (Kusakabe et al. 2002, Wang \& Urban 2007). Similar expression was also reported in catfish by IHC (Rajakumar \& Senthilkumaran 2015). Positive immunostaining of Cyp11c1/cyp11c1 was also detected in spermatogonia in zebrafish (Caulier et al. 2015), sea bass (Viñas \& Piferrer 2008) and Nile tilapia using a frog antibody (Zhang et al. 2010). In the present study, a tilapia-specific anti-Cyp11c1 polyclonal antibody was produced. By IHC, Cyp11c1 was found to be predominantly expressed in the testicular Leydig cells at 30, 90, 180 dah and head kidney inter-renal cells at 1 , 30, 90, 180 dah. No significant expression was observed in ovaries at any developmental stage, or in testes at 5 dah. No specific immunostaining was detected in spermatogonia in the present study. Previously, two alternatively spliced cyp11c1 isoforms were detected in testis and head kidney by RT-PCR and Northern blot (Zhang et al. 2010). However, only one band, corresponding to the longer isoform, was detected in the present study. This antibody recognizes both isoforms as the whole sequence of Cyp11c1 was used as antigen. We thus speculated that the short isoform was not translated into protein in tilapia. Cyp11c1 was also shown to be expressed in ovary in some fish species, such as honeycomb grouper and anemonefish (Alam et al. 2005, Miura et al. 2008). In this study, no Cyp11c1 expression was detected in tilapia ovary by IHC and Western blot, which is consistent with the results reported previously by our group (Zhang et al. 2010). Therefore, species differences in tissue expression of Cyp11c1 may exist in fishes.

\section{1-KT is critical for the initiation of spermatogenesis}

Androgens are necessary for spermatogenesis in mammals (Smith \& Walker 2014). In fish, the impact of androgens on spermatogenesis remains an ongoing debate. Unlike in mammals, 11-KT instead of testosterone is generally considered to be the major androgen in teleost fish (Borg 1994). On the one hand, it is well-documented that 11-KT is tightly associated with the process of spermatogenesis (Mayer et al. 1990, Kusakabe et al. 2002, Rajakumar \& Senthilkumaran 2015). 11-KT has been shown to induce all stages of spermatogenesis in Japanese eel in vitro (Miura et al. 1991). Exogenous 11-KT supplement promotes spermatogenesis in goldfish and Japanese huchen by inducing the initiation of spermatogonial proliferation (Kobayashi et al. 1991, Amer et al. 2001). In addition, African catfish treated with 11-KT displayed precocious spermatogonial proliferation and meiosis (Cavaco et al. 1998). Moreover, in tilapia, the initiation of spermatogenesis was reported to be significantly promoted by 11-KT in the presence of insulin-like growth factor 1 (IGF1) or human chorionic gonadotropin (hCG) (Tokalov $\&$ Gutzeit 2005). These results suggest that androgens are important for fish spermatogenesis. On the other hand, defective synthesis of androgens, caused by cyp $17 a 1$ deletion, did not result in spermatogenesis defects in medaka and zebrafish (Sato et al. 2008, Zhai et al. 2018). Zebrafish treated with flutamide (a specific antagonist of the androgen receptor) or subject to a complete shutdown of androgen signaling by AR knockout, still produce a small amount of viable sperm and are fertile (Yin et al. 2017, Tang et al. 2018). These results support the argument that androgens are not indispensable for spermatogenesis.

In the present study, loss of cyp11c1 resulted in sharply decreased serum cortisol and 11-KT. Meanwhile, a delayed spermatogenesis with only spermatogonia was observed in $c y p 11 c 1^{-/-}$testes at 90 dah, implying a possible role of cortisol or/and 11-KT in the initiation of spermatogenesis. The fact that delayed spermatogenesis could be rescued by 11-KT but not cortisol in cyp11c1-l- male suggests that 11-KT but not cortisol (at least not directly) contribute to the aberrant initiation of spermatogenesis. Overall, although the actions of other androgens in spermatogenesis could not be excluded in $c y p 11 c 1^{-l-}$ tilapia, the role of $11-\mathrm{KT}$ for the onset of spermatogenesis is noteworthy.

\section{1-KT is the most efficient androgen in teleost fish}

The androgenic effect of 11-KT was firstly identified in the male sockeye salmon (Idler et al. 1961). Since then, this steroid has been shown to be synthesized in the testis following gonadotropins stimulation in various teleost fish, resulting in high serum levels during spermatogenesis (Billard et al. 2017). Although the action of 11-KT in spermatogenesis has been proven in different species (Kobayashi et al. 1991, Miura et al. 1991, Cavaco et al. 1998, Amer et al. 2001), whether 11-KT is indispensable for fish spermatogenesis remains to be seen. In the present study, 11-KT synthesis was completely blocked by mutation of cyp11c1. Fish without 11-KT showed a delayed spermatogenesis, undersized testis but normal sperm motility. Here, two points need to be highlighted. 
First, the restored spermatogenesis in cyp11c1-/male at 180 dah might result from the compensation of other androgenic steroids in spermatogenesis. In this study, increased serum testosterone was detected both at 90 and 180 dah. Nevertheless, despite the elevated serum testosterone level, delayed spermatogenesis was still observed, indicating a higher potency of 11-KT than testosterone in the properinitiation of fish spermatogenesis. Furthermore, significantly reduced semen volume was observed in the cyp11c1-/- male, demonstrating a higher potency of 11-KT than testosterone in the promotion of fish spermatogenesis. DHT was generally considered to be produced only in tetrapods (Martyniuk et al. 2013). However, this steroid recently has been suggested to play an important role in some fish species (Margiotta-Casaluci \& Sumpter 2011, Margiotta-Casaluci et al. 2013, González et al. 2015, García-García et al. 2017). In the present study, increased serum DHT was detected in $c y p 11 c 1^{-1-}$ tilapia at 180 dah. Even though the elevated DHT level might be the consequence of testosterone accumulation, the possible role of DHT in the restoration of delayed spermatogenesis could not be excluded. This is also consistent with our previous study that showed some precursors of the 11-KT synthesis pathway, such as androstenedione, testosterone and DHT, could also act as androgens in tilapia (Shi et al. 2017). The exact role of DHT in fish reproduction needs to be further explored.

Second, $c y p 11 c 1^{-/-}$male tilapia displayed undersized testes with smaller efferent duct and disordered spermatogenic cysts. This is similar to AR-knockout zebrafish (Tang et al. 2018). The gonadotropins, FSH and LH are the most important pituitary hormones regulating testicular development (Koskenniemi et al. 2017). We thus wondered whether the defective testes in $c y p 11 c 1^{-/-}$fish were caused by gonadotropin insufficiency considering the highly elevated serum testosterone. Contrary to our expectations, increased expression of $f s h b, \mathrm{lhb}$ and their receptors, $f s h r, l h r$, was detected, indicating that the undersized testis in cyp11c1-/- male fish was a direct effect of 11-KT deficiency, instead of a negative feedback of increased testosterone to gonadotropin synthesis. These results indicate an incomparable role of 11-KT in fish testicular development. However, spermatogenesis was self-restored and small amounts of viable sperm were produced in cyp11c1-/- male tilapia. Taken together, these results demonstrated that $11-\mathrm{KT}$ is the most efficient androgen for fish testicular development, especially for the initiation and progression of spermatogenesis.

\section{The action of cortisol in spermatogenesis might be mediated by 11-KT}

Cortisol is the main glucocorticoid in teleost fish. The crosstalk between the cortisol and androgen pathways in temperature induced masculinization has been reported in several species (Hayashi et al. 2010, Fernandino et al. 2012). Whether the action of cortisol in testicular development and spermatogenesis is independent of androgens or not remains unclear. On the one hand, in Japanese eel, optimal levels of cortisol have been demonstrated to induce spermatogonial mitosis by increasing $11-\mathrm{KT}$ production (Ozaki et al. 2006). On the other hand, in common carp, restoration of serum 11-KT could not rescue the cortisolinduced retardation of testicular growth and the first wave of spermatogenesis (Consten et al. 2002), indicating an androgen-independent action of cortisol. In this study,
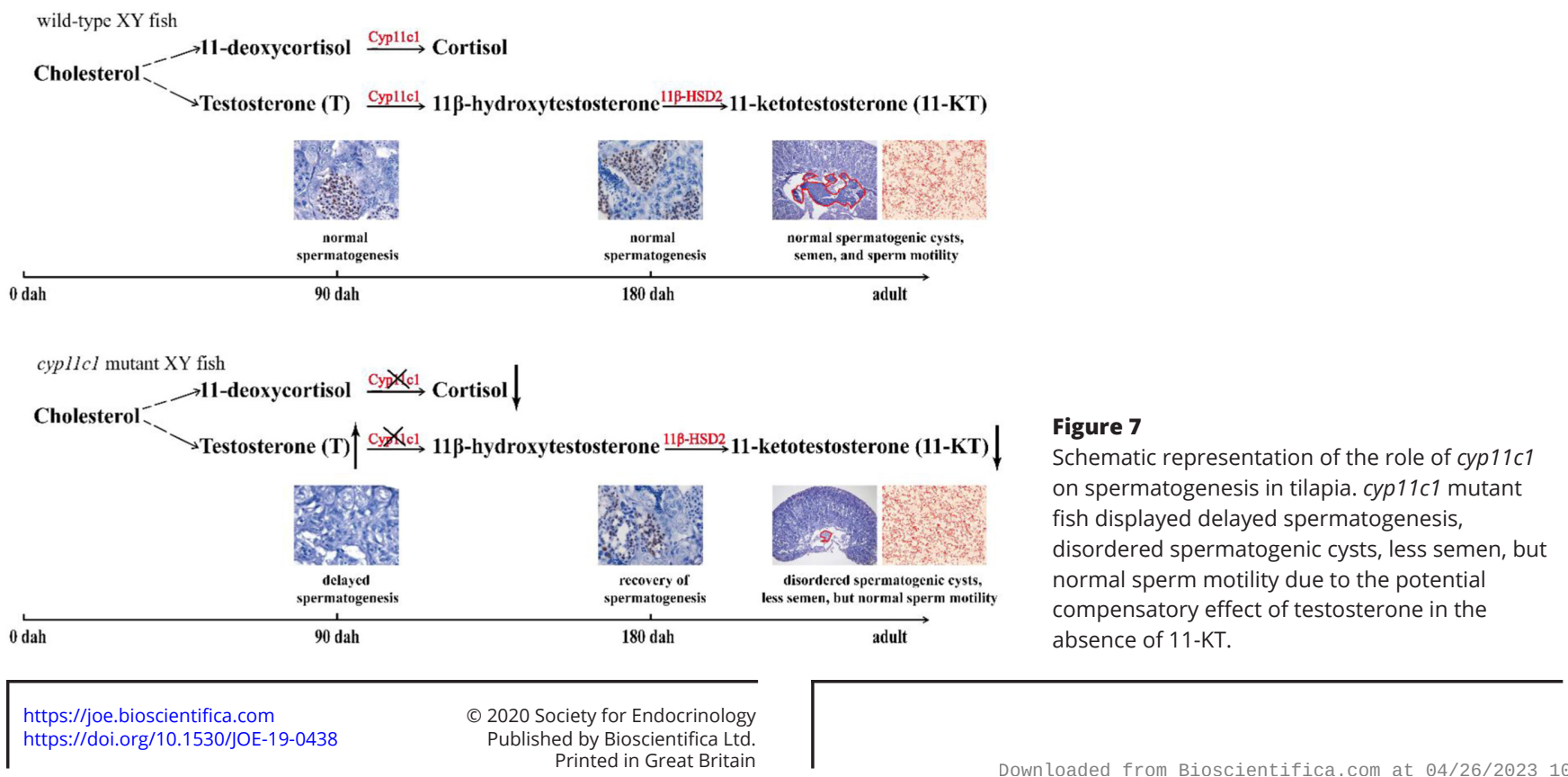

\section{Figure 7}

Schematic representation of the role of cyp11c1 disordered spermatogenic cysts, less semen, but normal sperm motility due to the potential compensatory effect of testosterone in the absence of 11-KT. 
exogenous cortisol supplement failed to rescue the delayed spermatogenesis in $c y p 11 c 1^{-/-}$fish, suggesting the action of cortisol in spermatogenesis might be 11-KT dependent. Our results could further serve as a new evidence for the crosstalk between cortisol and 11-KT.

In conclusion, loss of cyp11c1 in male tilapia caused delayed spermatogenesis at 90 dah, which could be rescued by exogenous 11-KT or testosterone, but not cortisol, indicating an important role of $11-\mathrm{KT}$ in the initiation of fish spermatogenesis. Notably, spermatogenesis was restored spontaneously at 180 dah, probably due to compensation by other androgenic steroids, such as testosterone or DHT. Furthermore, cyp11c1 ablation led to undersized testis with smaller efferent duct, disordered spermatogenic cysts and significantly reduced semen with viable sperm in adult tilapia (Fig. 7). These results suggest that $11-\mathrm{KT}$ is the most efficient androgen in tilapia.

\section{Supplementary materials}

This is linked to the online version of the paper at https://doi.org/10.1530/ JOE-19-0438.

\section{Declaration of interest}

The authors declare that there is no conflict of interest that could be perceived as prejudicing the impartiality of the research reported.

\section{Funding}

This work was supported by grants 31630082, 31572609, 31772830, 31872556, 31972778 and 31861123001 from the National Natural Science Foundation of China; grant 2018YFD0900202 from the National Key Research and Development Program of China.

\section{Author contribution statement}

Deshou Wang and Minghui Li conceived and designed the experiments; Qiaoyuan Zheng, Hesheng Xiao, Hongjuan Shi, Tingru Wang, Minghui Li, Lina Sun and Wenjing Tao performed the experiments; Deshou Wang, Qiaoyuan Zheng and Hesheng Xiao analyzed the data, interpreted the results and drafted the manuscript; Thomas D Kocher critically edited the manuscript. All authors read and approved the final manuscript.

\section{References}

Alam MA, Komuro H, Bhandari RK, Nakamura S, Soyano K \& Nakamura M 2005 Immunohistochemical evidence identifying the site of androgen production in the ovary of the protogynous grouper Epinephelus merra. Cell and Tissue Research 320 323-329. (https://doi. org/10.1007/s00441-004-1037-9)

Amer MA, Miura T, Miura C \& Yamauchi K 2001 Involvement of sex steroid hormones in the early stages of spermatogenesis in Japanese huchen (Hucho perryi). Biology of Reproduction 65 1057-1066. (https:// doi.org/10.1095/biolreprod65.4.1057)

Bain PA, Ogino Y, Miyagawa S, Iguchi T \& Kumar A 2015 Differential ligand selectivity of androgen receptors $\alpha$ and $\beta$ from MurrayDarling rainbowfish (Melanotaenia fluviatilis). General and Comparative Endocrinology 212 84-91. (https://doi.org/10.1016/j. ygcen.2015.01.024)

Bartlett JM, Kerr JB \& Sharpe RM 1986 The effect of selective destruction and regeneration of rat Leydig cells on the intratesticular distribution of testosterone and morphology of the seminiferous epithelium. Journal of Andrology 7 240-253. (https://doi. org/10.1002/j.1939-4640.1986.tb00924.x)

Bennett NC, Gardiner RA, Hooper JD, Johnson DW \& Gobe GC 2010 Molecular cell biology of androgen receptor signaling. International Journal of Biochemistry and Cell Biology 42 813-827. (https://doi. org/10.1016/j.biocel.2009.11.013)

Billard R, Fostier A \& Weil C 2017 Endocrine control of spermatogenesis in teleost fish. Journal Canadien des Sciences Halieutiques et Aquatiques 39 65-79. (https://doi.org/10.1139/f82-009)

Borg B 1994 Androgens in teleost fishes. Comparative Biochemistry and Physiology: Part C, Pharmacology, Toxicology and Endocrinology 109 219-245. (https://doi.org/10.1016/0742-8413(94)00063-G)

Caulier M, Brion F, Chadili E, Turies C, Piccini B, Porcher JM, Guiguen Y \& Hinfray N 2015 Localization of steroidogenic enzymes and Foxl2a in the gonads of mature zebrafish (Danio rerio). Comparative Biochemistry and Physiology: Part A, Molecular and Integrative Physiology 188 96-106. (https://doi.org/10.1016/j.cbpa.2015.06.016)

Cavaco JE, Vilrokx C, Trudeau VL, Schulz RW \& Goos HJ 1998 Sex steroids and the initiation of puberty in male African catfish (Clarias gariepinus). American Journal of Physiology 275 R1793-R1802. (https:// doi.org/10.1152/ajpregu.1998.275.6.R1793)

Chocu S, Calvel P, Rolland AD \& Pineau C 2012 Spermatogenesis in mammals: proteomic insights. Systems Biology in Reproductive Medicine 58 179-190. (https://doi.org/10.3109/19396368.2012.691943)

Consten D, Lambert JG, Komen H \& Goos HJ 2002 Corticosteroids affect the testicular androgen production in male common carp (Cyprinus carpio L). Biology of Reproduction 66 106-111. (https://doi.org/10.1095/ biolreprod66.1.106)

Conte MA, Gammerdinger WJ, Bartie KL, Penman DJ \& Kocher TD 2017 A high quality assembly of the Nile tilapia (Oreochromis niloticus) genome reveals the structure of two sex determination regions. BMC Genomics 18 341. (https://doi.org/10.1186/s12864-017-3723-5)

Cunningham GR \& Huckins C 1979 Persistence of complete spermatogenesis in the presence of low intratesticular concentrations of testosterone. Endocrinology 105 177-186. (https://doi.org/10.1210/ endo-105-1-177)

de Waal PP, Wang DS, Nijenhuis WA, Schulz RW \& Bogerd J 2008 Functional characterization and expression analysis of the androgen receptor in zebrafish (Danio rerio) testis. Reproduction 136 225-234. (https://doi.org/10.1530/REP-08-0055)

Fernandino JI, Hattori RS, Kishii A, Strüssmann CA \& Somoza GM 2012 The cortisol and androgen pathways cross talk in high temperature induced masculinization: the 11 beta-hydroxysteroid dehydrogenase as a key enzyme. Endocrinology 153 6003-6011. (https://doi. org/10.1210/en.2012-1517)

García-García M, Sánchez-Hernández M, García-Hernández MP, GarcíaAyala A \& Chaves-Pozo E 2017 Role of 5 $\alpha$-dihydrotestosterone in testicular development of gilthead seabream following finasteride administration. Journal of Steroid Biochemistry and Molecular Biology 174 48-55. (https://doi.org/10.1016/j.jsbmb.2017.07.024)

González A, Fernandino JI \& Somoza GM 2015 Effects of 5alphadihydrotestosterone on expression of genes related to steroidogenesis and spermatogenesis during the sex determination and differentiation periods of the pejerrey, Odontesthes bonariensis. Comparative Biochemistry and Physiology: Part A, Molecular and Integrative Physiology 182 1-7. (https://doi.org/10.1016/j.cbpa.2014.12.003) https://joe.bioscientifica.com

https://doi.org/10.1530/JOE-19-0438 (c) 2020 Society for Endocrinology Published by Bioscientifica Ltd. Printed in Great Britain 
Hayashi Y, Kobira H, Yamaguchi T, Shiraishi E, Yazawa T, Hirai T, Kamei Y \& Kitano T 2010 High temperature causes masculinization of genetically female medaka by elevation of cortisol. Molecular Reproduction and Development 77 679-686. (https://doi.org/10.1002/ mrd.21203)

Idler DR, Bitners II \& Schmidt PJ 1961 11-Ketotestosterone: an androgen for sockeye salmon. Canadian Journal of Biochemistry and Physiology 39 1737-1742. (https://doi.org/10.1139/o61-191)

Jiang JQ, Kobayashi T, Ge W, Kobayashi H, Tanaka M, Okamoto M, Nonaka Y \& Nagahama Y 1996 Fish testicular 11 $\beta$-hydroxylase: cDNA cloning and mRNA expression during spermatogenesis. FEBS Letters 397 250-252. (https://doi.org/10.1016/s0014-5793(96)01187-8)

Kobayashi M, Aida K \& Stacey NE 1991 Induction of testis development by implantation of 11-ketotestosterone in female goldfish. Zoological Science 8 389-393. (https://doi.org/10.1111/j.1096-3642.1991. tb00657.x)

Koskenniemi JJ, Virtanen HE \& Toppari J 2017 Testicular growth and development in puberty. Current Opinion in Endocrinology, Diabetes, and Obesity 24 215-224. (https://doi.org/10.1097/ MED.0000000000000339)

Kusakabe M, Kobayashi T, Todo T, Mark P, Nagahama Y \& Young G 2002 Molecular cloning and expression during spermatogenesis of a cDNA encoding testicular 11 $\beta$-hydroxylase $(\mathrm{P} 45011 \beta)$ in rainbow trout (Oncorhynchus mykiss). Molecular Reproduction and Development 62 456-469. (https://doi.org/10.1002/mrd.10145)

Li MH, Wu FR, Gu Y, Wang TR, Wang H, Yang SJ, Sun YL, Zhou LY, Huang XG, Jiao BW, et al. 2012 Insulin-like growth factor 3 regulates expression of genes encoding steroidogenic enzymes and key transcription factors in the Nile tilapia gonad. Biology of Reproduction 86 163, 1-163, 10. (https://doi.org/10.1095/biolreprod.111.096248)

Li MH, Yang HH, Zhao JE, Fang LL, Shi HJ, Li MR, Sun YL, Zhang XB, Jiang DN, Zhou LY, et al. 2014 Efficient and heritable gene targeting in tilapia by CRISPR/Cas9. Genetics 197 591-599. (https://doi. org/10.1534/genetics.114.163667)

Liu S, Govoroun M, D'Cotta H, Ricordel MJ, Lareyre JJ, McMeel OM, Smith T, Nagahama Y \& Guiguen Y 2000 Expression of cytochrome P450(11beta) (11beta-hydroxylase) gene during gonadal sex differentiation and spermatogenesis in rainbow trout, Oncorhynchus mykiss. Journal of Steroid Biochemistry and Molecular Biology $\mathbf{7 5}$ 291-298. (https://doi.org/10.1016/s0960-0760(00)00186-2)

Liu Y, Yao ZX, Bendavid C, Borgmeyer C, Han Z, Cavalli LR, Chan WY, Folmer J, Zirkin BR, Haddad BR, et al. 2005 Haploinsufficiency of cytochrome P450 17 $\alpha$-hydroxylase/17,20 lyase (CYP17) causes infertility in male mice. Molecular Endocrinology 19 2380-2389. (https://doi.org/10.1210/me.2004-0418)

Liu JF, Guiguen Y \& Liu SJ 2009 Aromatase (P450arom) and $11 \beta$-hydroxylase (P45011 $\beta$ ) genes are differentially expressed during the sex change process of the protogynous rice field eel, Monopterus albus. Fish Physiology and Biochemistry 35 511-518. (https://doi. org/10.1007/s10695-008-9255-9)

Livak K \& Schmittgen T 2000 Analysis of relative gene expression data using real-time quantitative PCR and the $2^{-\Delta \Delta C t}$ method. Methods 25 402-408. (https://doi.org/10.1006/meth.2001.1262)

Margiotta-Casaluci L \& Sumpter JP $20115 \alpha$-Dihydrotestosterone is a potent androgen in the fathead minnow (Pimephales promelas). General and Comparative Endocrinology 171 309-318. (https://doi. org/10.1016/j.ygcen.2011.02.012)

Margiotta-Casaluci L, Courant F, Antignac JP, Le Bizec B \& Sumpter JP 2013 Identification and quantification of $5 \alpha$-dihydrotestosterone in the teleost fathead minnow (Pimephales promelas) by gas chromatography-tandem mass spectrometry. General and Comparative Endocrinology 191 202-209. (https://doi.org/10.1016/j. ygcen.2013.06.017)

Martyniuk CJ, Bissegger S \& Langlois VS 2013 Current perspectives on the androgen 5 alpha-dihydrotestosterone (DHT) and 5 alpha-reductases in teleost fishes and amphibians. General and
Comparative Endocrinology 194 264-274. (https://doi.org/10.1016/j. ygcen.2013.09.019)

Mayer I, Borg B \& Schulz R 1990 Seasonal changes in and effect of castration/androgen replacement on the plasma levels of five androgens in the male three-spined stickleback, Gasterosteus aculeatus L. General and Comparative Endocrinology 79 23-30. (https://doi. org/10.1016/0016-6480(90)90084-y)

Miller WL 1988 Molecular biology of steroid hormone synthesis. Endocrine Reviews 9 295-318. (https://doi.org/10.1210/edrv-9-3-295)

Miura T, Yamauchi K, Takahashi H \& Nagahama Y 1991 Hormonal induction of all stages of spermatogenesis in vitro in the male Japanese eel (Anguilla japonica). PNAS 88 5774-5778. (https://doi.org/10.1073/ pnas.88.13.5774)

Miura S, Horiguchi R \& Nakamura M 2008 Immunohistochemical evidence for 11beta-hydroxylase (P45011beta) and androgen production in the gonad during sex differentiation and in adults in the protandrous anemonefish Amphiprion clarkii. Zoological Science $\mathbf{2 5}$ 212-219. (https://doi.org/10.2108/zsj.25.212)

Mommsen TP, Vijayan MM \& Moon TW 1999 Cortisol in teleosts: dynamics, mechanisms of action, and metabolic regulation. Reviews in Fish Biology and Fisheries 9 211-268. (https://doi. org/10.1023/A:1008924418720)

Nakamura M \& Nagahama Y 1989 Differentiation and development of Leydig cells, and change of testosterone levels during testicular differentiation in tilapia, Oreochromis niloticus. Fish Physiology and Biochemistry 7 211-219. (https://doi.org/10.1007/BF00004709)

Nishimura H \& L'Hernault SW 2017 Spermatogenesis. Current Biology 27 R988-R994. (https://doi.org/10.1016/j.cub.2017.07.067)

O'Hara L \& Smith LB 2015 Androgen receptor roles in spermatogenesis and infertility. Best Practice and Research: Clinical Endocrinology and Metabolism 29 595-605. (https://doi.org/10.1016/j. beem.2015.04.006)

Ozaki Y, Higuchi M, Miura C, Yamaguchi S, Tozawa Y \& Miura T 2006 Roles of 11 beta-hydroxysteroid dehydrogenase in fish spermatogenesis. Endocrinology 147 5139-5146. (https://doi. org/10.1210/en.2006-0391)

Rajakumar A \& Senthilkumaran B 2015 Dynamic expression of $11 \beta$-hydroxylase during testicular development, recrudescence and after hCG induction, in vivo and in vitro in catfish, Clarias batrachus. General and Comparative Endocrinology 211 69-80. (https://doi. org/10.1016/j.ygcen.2014.11.010)

Schulz RW \& Miura T 2002 Spermatogenesis and its endocrine regulation. Fish Physiology and Biochemistry 26 43-56. (https://doi. org/10.1023/A:1023303427191)

Russell LD \& Clermont Y 1977 Degeneration of germ cells in normal, hypophysectomized and hormone treated hypophysectomized rats. Anatomical Record 187 347-366. (https://doi.org/10.1002/ ar.1091870307)

Sato T, Suzuki A, Shibata N, Sakaizumi M \& Hamaguchi S 2008 The novel mutant scl of the medaka fish, Oryzias latipes, shows no secondary sex characters. Zoological Science 25 299-306. (https://doi.org/10.2108/ zsj.25.299)

Schulz RW, de Franca LR, Lareyre JJ, Le Gac F, Chiarini-Garcia H, Nobrega RH \& Miura T 2010 Spermatogenesis in fish. General and Comparative Endocrinology 165 390-411. (https://doi.org/10.1016/j. ygcen.2009.02.013)

Shi HJ, Gao T, Liu ZL, Sun LN, Jiang XL, Chen LL \& Wang DS 2017 Blockage of androgen and administration of estrogen induce transdifferentiation of testis into ovary. Journal of Endocrinology 233 65-80. (https://doi.org/10.1530/JOE-16-0551)

Smith LB \& Walker WH 2014 The regulation of spermatogenesis by androgens. Seminars in Cell and Developmental Biology 30 2-13. (https://doi.org/10.1016/j.semcdb.2014.02.012)

Socorro S, Martins RS, Deloffre L, Mylonas CC \& Canario AV 2007 A cDNA for European sea bass (Dicentrachus labrax) 11 $\beta$-hydroxylase: gene expression during the thermosensitive period and https://joe.bioscientifica.com

https://doi.org/10.1530/JOE-19-0438 (c) 2020 Society for Endocrinology Published by Bioscientifica Ltd. Printed in Great Britain 
gonadogenesis. General and Comparative Endocrinology 150 164-173. (https://doi.org/10.1016/j.ygcen.2006.07.018)

Sun YL, Jiang DN, Zeng S, Hu CJ, Ye K, Yang C, Yang SJ, Li MH \& Wang DS 2014 Screening and characterization of sex-linked DNA markers and marker-assisted selection in the Nile tilapia, (Oreochromis niloticus). Aquaculture 433 19-27. (https://doi.org/10.1016/j. aquaculture.2014.05.035)

Tang H, Chen Y, Wang L, Yin Y, Li G, Guo Y, Liu Y, Lin H, Cheng CHK \& Liu X 2018 Fertility impairment with defective spermatogenesis and steroidogenesis in male zebrafish lacking androgen receptor. Biology of Reproduction 98 227-238. (https://doi.org/10.1093/biolre/iox165)

Todd EV, Liu H, Muncaster S \& Gemmell NJ 2016 Bending genders: the biology of natural sex change in fish. Sexual Development 10 223-241. (https://doi.org/10.1159/000449297)

Tokalov SV \& Gutzeit HO 2005 Spermatogenesis in testis primary cell cultures of the tilapia (Oreochromis niloticus). Developmental Dynamics 233 1238-1247. (https://doi.org/10.1002/dvdy.20379)

Viñas J \& Piferrer F 2008 Stage-specific gene expression during fish spermatogenesis as determined by laser-capture microdissection and quantitative-PCR in sea bass (Dicentrarchus labrax) gonads. Biology of Reproduction 79 738-747. (https://doi.org/10.1095/ biolreprod.108.069708)

Walker WH 2010 Non-classical actions of testosterone and spermatogenesis. Philosophical Transactions of the Royal Society of
London: Series B, Biological Sciences 365 1557-1569. (https://doi. org/10.1098/rstb.2009.0258)

Wang XG \& Urban L 2007 Anti-Mullerian hormone and 11b-hydroxylase show reciprocal expression to that of aromatase in the transforming gonad of zebrafish males. Developmental Dynamics 236 1329-1338. (https://doi.org/10.1002/dvdy.21129)

Yin P, Li YW, Chen QL \& Liu ZH 2017 Diethylstilbestrol, flutamide and their combination impaired the spermatogenesis of male adult zebrafish through disrupting HPG axis, meiosis and apoptosis. Aquatic Toxicology 185 129-137. (https://doi.org/10.1016/j. aquatox.2017.02.013)

Zhai G, Shu T, Xia Y, Lu Y, Shang G, Jin X, He J, Nie P \& Yin Z 2018 Characterization of sexual trait development in cyp17a1-deficient zebrafish. Endocrinology 159 3549-3562. (https://doi.org/10.1210/ en.2018-00551)

Zhang FP, Poutanen M, Wilbertz J \& Huhtaniemi I 2001 Normal prenatal but arrested postnatal sexual development of luteinizing hormone receptor knockout (LuRKO) mice. Molecular Endocrinology 15 172-183. (https://doi.org/10.1210/mend.15.1.0582)

Zhang WL, Zhou LY, Senthilkumaran B, Huang BF, Sudhakumari CC, Kobayashi T, Nagahama Y \& Wang DS 2010 Molecular cloning of two isoforms of $11 \beta$-hydroxylase and their expressions in the Nile tilapia, Oreochromis niloticus. General and Comparative Endocrinology 165 34-41. (https://doi.org/10.1016/j.ygcen.2009.05.018)

Received in final form 13 December 2019

Accepted 7 January 2020

Accepted Manuscript published online 7 January 2020 (c) 2020 Society for Endocrinology Published by Bioscientifica Ltd.
Printed in Great Britain 